Original Research Article

\title{
Pattern of adverse drug reactions reporting in two medical colleges of Tripura, India: a cross sectional study
}

\author{
Anannya Chakraborty ${ }^{1}$, Debasis Ray ${ }^{2 *}$, Ranjib Ghosh ${ }^{1}$, Nibedita Roy ${ }^{3}$, Sayan Bhattacharje ${ }^{1}$
}

${ }^{1}$ Department of Pharmacology, TMC and Dr. BRAM Teaching Hospital, Hapania, Po. ONGC, Agartala, India

${ }^{2}$ Department of Pharmacology, Agartala Govt. Medical College, Po. Kunjavan, Agartala, India ${ }^{3}$ Department of Pharmacology, ADR Monitoring Center (AMC), Agartala Govt. Medical College, Po. Kunjavan, Agartala, India

Received: 16 March 2017 Accepted: 22 April 2017

*Correspondence to:

Dr. Debasis Ray, Email: contactdebasisray@ gmail.com

Copyright: (C) the author(s), publisher and licensee Medip Academy. This is an openaccess article distributed under the terms of the Creative Commons Attribution NonCommercial License, which permits unrestricted noncommercial use, distribution, and reproduction in any medium, provided the original work is properly cited.

\begin{abstract}
Background: India as an important clinical trial hub in the world. In clinical trials, many of the drug issues related to the safety are inadequately studied in highly selected and limited number of patients. Due to introduction of many new drugs in the country, it has become essential to have an effective Pharmacovigilance system nationwide. Under reporting of ADRs is widespread and a daunting challenge in Pharmacovigilance programme of India (PvPI).

Methods: A cross sectional study was conducted for two months with the objective to study the pattern of ADRs reporting in two teaching hospitals of Tripura. The data were collected in "Suspected ADR reporting forms" of Indian Pharmacopoeia Commission (IPC). Suspected ADRs were assessed for causality using Naranjo ADR probability scale.

Results: 44 ADR reporting forms were received with 58 ADRS. Among them, Gastrointestinal System ADRs were the highest (25.86\%). More ADRs were seen in males than females $(52.27 \%$ vs $47.72 \%)$. $68.18 \%$ cases had the medication through oral route. Out of all ADRs, $67.24 \%$ were Type A reactions. Most of the reactions reported, were mild (90.9\%) based on modified Hartwig severity scale. Most of the ADRs reported were of probable causality (score 59) measured by Naranjo's Algorithm.

Conclusions: This study would definitely give an insight into the pattern of ADRs in tertiary health care centers and may help to increase awareness of health care provider for further Pharmacovigilance studies.
\end{abstract}

Keywords: ADR reporting, Causality, Naranjo's Algorithm, Pharmacovigilance

\section{INTRODUCTION}

Adverse drug reaction (ADR) is "a response to a drug that is noxious and unintended and occurs at doses normally used in man for the prophylaxis, diagnosis or therapy of disease, or for modification of physiological function." All drugs are having the potential to cause ADRs. ${ }^{2}$ ADRs are a major cause of morbidity. ADRs related hospitalizations have consistently increased which has caused an economic burden to the developing countries like India. ${ }^{3}$ ADRs are commonly encountered at hospital set up where poly pharmacy is practiced usually. ${ }^{4}$

Primarily, India and other countries have a spontaneous or voluntary system of ADR monitoring. So, an ADR often goes unnoticed due to the following reasons:

a) Failure of recognition of ADRs by patient or his relatives because of lack of sensitization

b) Inadequate risk perception of newly marketed drugs 
c) Insufficient training of health care professionals to recognize ADRs. ${ }^{5-7}$

In clinical trials, many of the drug issues related to the safety are inadequately studied in highly selected and limited number of patients, so that the exact safety profile of the drug in the real-life situations is not known. Children, pregnant women, and elderly are not included in clinical trials for ethical reasons. The safety of the drug in these cases remains unknown until its release. Another important drawback of clinical trials is that they can only report adverse reactions that appear within the finite duration of trial. Delayed reactions would be missed. ${ }^{8}$

India is the fourth largest pharmaceutical producer in the world and is recognized as an important clinical trial hub in the world. Due to introduction of many new drugs in the country, it has become essential to have an effective Pharmacovigilance system nationwide in order to protect interest of public health. The main function of this programme involves data collection and analysis of ADRs. ${ }^{7}$

Under reporting of ADRs is widespread and a daunting challenge in Pharmacovigilance programme of India (PvPI). Unawareness of Pharmacovigilance programme, lack of knowledge, ignorance, lethargy, indifference, insecurity, complacency, overwork and lack of training are some of the important causes of underreporting of ADRs among the health care professionals of India. ${ }^{9}$

Two medical colleges have been established in Tripura in resent past and these two medical colleges get the bulk of the patients from Tripura. So, a rough idea about the pattern of ADR reporting can be anticipated and based on such type of study further intervention can be planned to improve the ADR reporting by the Health care providers of Tripura. Moreover, no recent study was conducted to evaluate the pattern of ADR reporting practice in Tripura.

Hence, considering the above facts present study was undertaken with the objective to identify the pattern of ADRs reporting practice at two Medical Colleges of Tripura.

\section{METHODS}

Design of the study was cross sectional.

\section{Study setting}

In patients Departments (IPDs) at TMC and AGMC.

Duration of study was two months (May 2016 to June 2016).

\section{Participants}

All the spontaneous ADR reports reported during the study period of May 2016 to June 2016 were included.

\section{Data sources}

All the ADRs reported from the admitted patients in Tripura Medical College (TMC) and Agartala Govt. Medical College (AGMC) during the study period were included in the study. The patients were either admitted with ADRs due to drugs used outside the hospital or developed ADRs during the course of treatment in the hospital.

"Suspected ADR Reporting Form Version -1.2 of Indian Pharmacopoeia Commission (IPC) was used to fill up the ADRs by health care professionals of in patients Departments (IPD) at TMC and AGMC.

\section{Variables}

For each patient the "Suspected ADR Reporting Form" was completed with regard to: Age of the patient, Gender of the patient, Number of drug(s) prescribed, Duration of treatment (days), Causality of the ADR(s), Severity of the identified ADR(s), Route of administration of suspected medications, Frequency of administration of suspected drug Type of ADR(s).

Suspected ADRs were assessed for causality using Naranjo ADR probability scale. ${ }^{10}$ The degree of association of an ADR with a drug was done with the help of Naranjo's algorithm which involves assigning score to set of questions. The total score for a particular ADR was calculated and the association was termed into one of these categories - certain (score >9), probable (score 5-8), possible (score 1-4) or unlikely (score 0 ).

Severity was identified using modified Hartwig's criteria which involve seven severity levels. ${ }^{11}$ Severity of the identified ADRs was assessed at different levels, ranging between 1 and 7. Levels 1 and 2 indicated mild, 3 and 4 considered as moderate and level 5 and above as severe ADRs. Types of ADRs were identified using Rawlins and Thompson classification. ${ }^{12}$

\section{Sample size}

All the 44 voluntary ADR reports, reported during the study period were included and analyzed.

\section{Statistical analysis}

The data were compiled on a Microsoft excel sheet and was subjected to descriptive statistical analysis.

Profile of patients like age, gender, number of drugs prescribed, duration of treatment, the responsible drug(s) for ADRs with causality assessment, severity of the identified ADRs, route of administration of suspected medications, frequency of administration of suspected drug and type of ADRs were represented as percentage. 


\section{RESULTS}

In 52 working days, over a period of 2 months, total 58 (fiftyeight) ADRs were reported from 44 (forty four) patients.

Types of ADRs with their numbers and suspected drug/drugs are shown in Table-I. Out of 58 ADRs, the most commonly identified ADRs were related to gastrointestinal system disorders $(25.86 \%)$ followed by skin and appendages disorders (20.68\%). The ADRs related to General Body Disorders were $18.96 \%$ and central and peripheral nervous system disorders were $15.51 \%$. ADRs related to other systems (musculo-skeletal system disorders, respiratory system disorders and endocrine system disorders) were $18.99 \%$.

Table 1: Types of ADRs with their numbers $(\mathrm{N}=58)$ and suspected drug/drugs.

\begin{tabular}{|c|c|c|}
\hline ADRs & Number & Drug/drugs involved \\
\hline \multicolumn{3}{|c|}{ Skin and appendages disorder $[\mathrm{N}=12(20.68 \%)]$} \\
\hline Mucosal irritation & 01 & Piperacillin+Tazobactum \\
\hline Generalised itching & 05 & Clindamycin, Cefotaxime, Ceftriaxone, Paracetamol, Ceftriaxone+Sulbactam \\
\hline Itching on palm and lips & 01 & Ofloxacin+Ornidazole \\
\hline Rash & 03 & Ofloxacin+Ornidazole, Ceftriaxone+Sulbactam, Antirabies vaccine \\
\hline Steven Johnson Syndrome & 01 & Sulfasalazine \\
\hline Fixed Drug Eruption & 01 & Ofloxacin+Ornidazole \\
\hline \multicolumn{3}{|c|}{ Gastrointestinal system disorders $[\mathrm{N}=15(25.86 \%)]$} \\
\hline Nausea & 01 & Ceftriaxone Sodium+Sulbactam \\
\hline Vomiting & 02 & Cefuroxime axetil+Linezolid, Tramadol+Paracetmol \\
\hline Oral Ulcer & 01 & Ofloxacin+Ornidazole \\
\hline Abdominal Pain & 01 & Aceclofenac+Paracetamol \\
\hline \multirow[t]{2}{*}{ Gastritis } & 07 & Aceclofenac (2), Etodolac, Aceclofenac+Paracetamol (3), \\
\hline & & INH+Rifampicin+Ethambutol+Pyrazinamide \\
\hline Loose stool & 02 & Piperacillin+Tazobactum, Alendronte sodium \\
\hline Jaundice & 01 & Tenofovir+Lamivudin+Efavirenz \\
\hline \multicolumn{3}{|c|}{ Central and Peripheral Nervous System Disorders $[\mathrm{N}=09(15.51 \%)]$} \\
\hline Akathisia & 03 & Pregabalin, Aceclofenac, Risperidone \\
\hline Headache & 01 & Tramadol+Paracetamol \\
\hline Extrapyramidal side effects & 02 & Risperidone, Aripiprazole \\
\hline Dyskinesia & 01 & Risperidone \\
\hline Dizziness & 02 & Pregabalin+Methyl cobalamin, Tramadol+Paracetamol \\
\hline \multicolumn{3}{|c|}{ Musculoskeletal System Disorders [N=03(5.17\%)] } \\
\hline Pain in joint & 02 & Cefepime+Tazobactam, Ofloxacin \\
\hline Back pain & 01 & Amikacin \\
\hline \multicolumn{3}{|c|}{ General Body Disorders $[\mathrm{N}=11(18.96 \%)]$} \\
\hline Fever & 01 & Piperacillin+Tazobactam \\
\hline \multirow[t]{2}{*}{ Generalised oedema } & 05 & Cefepime+Tazobactam, Iohexol,Iopromide, Cefotaxime, Telmisartan, \\
\hline & & Teneli gliptin, Atorvastatin \\
\hline Pedal oedema & 03 & Amlodipine, Etoricoxib, Ofloxacin \\
\hline Generalised weakness & 02 & Cefuroxime axetil + Linezolid, Tramadol+Paracetamol \\
\hline \multicolumn{3}{|c|}{ Respiratory System Disorder [N=07(12.06\%)] } \\
\hline Sneezing and running nose & 04 & Iohexol, Iopromide, Ciprofloxacin, Ceftriaxone \\
\hline Nasal Congestion & 01 & Risperidone \\
\hline Breathing Difficulty & 02 & Ceftriaxone sodium, INH+Rifampicin+Ethambutol+Pyrazinamide \\
\hline \multicolumn{3}{|c|}{ Endocrine disorders $[\mathrm{N}=01(1.72 \%)]$} \\
\hline Galactorrhoea & 01 & Rabeprazole \\
\hline
\end{tabular}

Figures in parenthesis against the name of the drug indicate the frequency of occurrence of each reaction by the concerned drug

Profile of patients suffering from ADRs $(\mathrm{N}=44)$ is shown in Table 2. Out of 44 patients, majority of the patients $(81 \%)$ were between $12-59$ years. There was preponderance of ADRs in males as compared to females
(52.27\% vs $47.72 \%$ ). $90.9 \%$ patients were on less than 6 medications while $6.81 \%$ and $2.27 \%$ of the patients were on 6-10 medications and more than 10 medications respectively. Causality assessment was done with the 
help of Naranjo's algorithm. Causality for $36.36 \%$, $56.81 \%$, and $6.81 \%$ cases were possible (score 1-4), probable (score 5-8) and certain (score >9) respectively.

Table 2: Profile of patients suffering from ADRs (N=44).

\begin{tabular}{|c|c|c|c|}
\hline \multicolumn{2}{|l|}{ Characteristics } & \multicolumn{2}{|c|}{$\mathbf{N}(\%)$} \\
\hline Age (in years) & $<12$ & 02 & $(4.54)$ \\
\hline & $12-59$ & 36 & $(81)$ \\
\hline & $60-90$ & 06 & (13.63) \\
\hline \multirow{2}{*}{ Gender } & Female & 21 & $(47.72)$ \\
\hline & Male & 23 & $(52.27)$ \\
\hline \multirow[t]{3}{*}{$\begin{array}{l}\text { Number of } \\
\text { medication(s) }\end{array}$} & $<6$ & 40 & $(90.9)$ \\
\hline & $6-10$ & 03 & $(6.81)$ \\
\hline & $>10$ & 01 & $(2.27)$ \\
\hline \multirow[t]{2}{*}{$\begin{array}{l}\text { Duration of treatment } \\
\text { (in days) }\end{array}$} & $<10$ & 38 & (86.36) \\
\hline & $>10$ & $6(1$ & .63) \\
\hline \multirow[t]{4}{*}{ Causality } & Unlikely & $0(0$ & \\
\hline & Possible & 16 & (36.36) \\
\hline & Probable & 25 & $(56.81)$ \\
\hline & Certain & 03 & $(6.81)$ \\
\hline \multirow[t]{3}{*}{ Severity of ADRs } & Mild & 40 & (90.9) \\
\hline & Moderate & $0(0$ & \\
\hline & Severe & 04 & $(9.09)$ \\
\hline \multirow[t]{4}{*}{$\begin{array}{l}\text { Route of } \\
\text { administration }\end{array}$} & Oral & 30 & $(68.18)$ \\
\hline & I.V. & 12 & $(27.27)$ \\
\hline & I.M. & 01 & $(2.27)$ \\
\hline & S.C. & 01 & $(2.27)$ \\
\hline \multirow[t]{5}{*}{$\begin{array}{l}\text { Frequency of } \\
\text { administration }\end{array}$} & Once daily & 15 & (34.09) \\
\hline & Twice daily & 16 & $(36.36)$ \\
\hline & Thrice daily & 06 & $(13.63)$ \\
\hline & Once only & 06 & $(13.63)$ \\
\hline & Once weekly & 01 & $(2.27)$ \\
\hline \multirow[t]{2}{*}{ Type of ADRs } & Type-A & 39 & $(67.24)$ \\
\hline & Type-B & 19 & $(32.76)$ \\
\hline
\end{tabular}

Based on modified Hartwig severity scale, 90.9\% reactions were mild and $9.09 \%$ were severe. Among the cases of ADRs reported, $68.18 \%$ cases had the medication through oral route and $27.27 \%$ cases had the medication through intravenous (IV) route. Frequency of administration of drugs for most of the cases was twice daily $(36.6 \%)$. Out of all ADRs, $67.24 \%$ was type-A reactions while $32.76 \%$ was type-B reactions.

\section{DISCUSSION}

ADRs are distressing to both the patients and physicians. Severe ADRs may lead to mortality, prolongation of hospital stay and increased cost of the treatment.
The reported 58 ADRs were categorized by Rawlins and Thompson classification and correlation of various types of ADRs among study subjects were established. In the present study, gastrointestinal system related ADRs were the highest $(25.86 \%)$. Gor AP et al in their study also demonstrated highest incidence $(66.67 \%)$ of ADRs related to gastrointestinal system. ${ }^{13}$ Next system involved was skin and appendages disorders $(20.68 \%)$. Saha A et al demonstrated that the incidence of Stevens Johnson syndrome, Toxic epidermal necrolysis and overlap of two was $24.50 \%$. In the present study, $8.33 \%$ ADRs of skin and appendage disorders were life threatening Stevens Johnson syndrome which is in contrast to the findings of Saha A et al. ${ }^{14}$ The variation of results may be due to shorter duration of our study period. The remaining systems affected were body as whole-general disorders $(18.96 \%)$, central and peripheral nervous system disorders $(15.51 \%)$ and other systems $(18.99 \%)$.

Profile of the patients like age, gender, number of medications, duration of treatment, causality of the $\operatorname{ADR}(s)$, Severity of the identified $\operatorname{ADR}(s)$, route of administration of suspected medications, frequency of administration of suspected drug, type of $\operatorname{ADR}(s)$ were also assessed. Age is an important risk factor for ADRs and incidence of ADRs increases in elderly patients. Mahesh NB et al reported the proportion of patients suffering from ADRs aged <18, 18-65 and >65 years were $15.5 \%, 80.1 \%$, and $4.4 \%$, respectively. ${ }^{15}$ In this study, majority of ADRs (81\%) were observed in the age group between $12-59$ years. Some studies have reported a higher incidence of ADRs in females. ${ }^{16}$ Gor AP et al reported that there was no influence of sex on the occurrence rate of ADRs. ${ }^{13}$ In this study higher incidence is seen in males $(52.27 \%)$ in comparison to females $(47.72 \%)$. It is a well- established fact that as the number of drugs increases, the chance of developing ADR also increases. ${ }^{13}$ Earlier studies have documented, most of the ADRs develop within the first 10 days of administering the drug. ${ }^{17}$ In the present study, $86.36 \%$ patients developed ADRs within 10 days of treatment while $13.63 \%$ patients developed ADRs after 10 days of treatment. This emphasizes the need of observing the patients closely in the initial period of treatment. The results of this study showed that the most common causality category using the Naranjo algorithm was probable $(56.81 \%)$ which substantiates the findings of Macedo et. al and Lei et. Al. ${ }^{18,19}$ Most of the ADRs were mild (90.9\%). 67.24\% ADRs belong to type A (augmented) reactions. As such, out of all ADRs, $80 \%$ of the reactions are of type $\mathrm{A}^{19}$ and hence our finding is not surprising.

\section{CONCLUSION}

This study shows ADRs are very common in the two tertiary health care teaching hospitals in Tripura. Most of these ADRs are preventable as there is higher incidence of type A reactions. Although the present study has some limitations as it is an analytical study for very short 
duration, still this study would definitely give an insight into the pattern of ADRs in tertiary health care centers and may help to increase awareness for further Pharmacovigilance studies.

\section{ACKNOWLEDGMENTS}

This study was done under STS programme by ICMR. The authors are grateful to the ICMR, Principal of TMC and Dr. BRAM Teaching Hospital and Principal, Agartala Govt. Medical College, and GBP Hospital, Agartala, Tripura for providing the necessary facilities to carry out this work. The authors are also grateful to the health care providers who have reported the ADRs to the ADR monitoring centers of two medical colleges to carry out this study.

\section{Funding: No funding sources}

Conflict of interest: None declared

Ethical approval: The study was approved by the Institutional Ethics Committee

\section{REFERENCES}

1. Edwards IR and Aronson JK. Adverse drug reactions: definitions, diagnosis, and management. Lancet. 2000;356:1255-59.

2. Tripathi KD. Essentials of Medical Pharmacology, JP Brothers, $7^{\text {th }}$ Ed, New Delhi; 2013:82-91.

3. Zhang M, Holman CDJ, Preen DB, Brameld K. Repeat adverse drug reactions causing hospitalization in older Australians: a population-based longitudinal study 1980-2003. Br J Clin Pharmacol. 2007;63:16370.

4. Kaur S, Kapoor V, Mahajan R, Lal M, Gupta S. Monitoring of incidence, severity, and causality of adverse drug reactions in hospitalized patients with cardiovascular disease. Indian $\mathrm{J}$ Pharmacol. 2011;43(1):22-6.

5. Tandon VR, Mahajan V, Khajuria V, Gillani Z, Under-reporting of adverse drug reactions: A challenge for pharmacovigilance in India. Indian $\mathrm{J}$ Pharmacol. 2015;47(1):65-71.

6. Rehan HS, Sah RK, Chopra D. Comparison of knowledge, attitude and practices of resident doctors and nurses on adverse drug reaction monitoring and reporting in a tertiary care hospital. Indian Journal of Pharmacol. 2012;44:699-703.

7. Patil JS. Pharmacovigilance in India. J Pharmacovigilance. 2014;2:2.

8. Dhikav V, Singh S, Anand KS. Adverse Drug Reaction Monitoring in India. Journal, Indian Academy of Clinical Medicine. 2004;5(1):27-33.
9. Tandon VR, Mahajan V, Khajuria V, Gillani Z. Under-reporting of adverse drug reactions: A challenge for pharmacovigilance in India. Indian Journal of Pharmacology. 2015;47:68-71.

10. Naranjo CA, Busto U, Sellers EM, Sandor P, Ruiz I, Roberts EA. A method for estimating the probability of adverse drug reactions. Clin Pharmacol Ther. 1981;30:239-45.

11. Hartwig SC, Siegel J, Schneider PJ. Preventability and severity assessment in reporting adverse drug reactions. Am J Hosp Pharm. 1992;49:2229-32.

12. Rawlins MD, Thompson JW. Pathogenesis of adverse drug reactions. In: Davies DM, editor. Textbook of adverse drug reactions. Vol 10. $1^{\text {st }}$ Edition Oxford: Oxford University Press; 1977:27.

13. Gor AP, Desai SV. Adverse Drug Reactions (ADR) in the inpatients of Medicine Department of a Rural Tertiary Care Teaching Hospital and Influence of Pharmacovigilance in Reporting ADR. Indian $\mathbf{J}$ Pharmacol. 2008;40(1):37-40.

14. Saha A, Das NK, Hazra A, Gharami RC, Chowdhury SN, Datta PK. Cutaneous adverse drug reaction profile in a tertiary care outpatient setting in Eastern India. Indian J Pharmacol. 2012;44(6):792-7.

15. Belhekar MN, Taur SR, Munshi RP. A study of agreement between the Naranjo algorithm and WHOUMC criteria for causality assessment of adverse drug reactions. Indian J Pharmacol. 2014;46(1):11720.

16. Schwartz JB. The influence of sex on pharmacokinetics. Clin Pharmaco. 2003;42:107-21.

17. Eileen G, Hollcend, Phevm D, Frank V. Degrig M.D. Drug induced disorder D. Family Physician. 1997;2:10.

18. Macedo AF, Marques FB, Ribeiro CF, Teixeira F. Causality assessment of adverse drug reactions: comparison of the results obtained from published decisional algorithms and from the evaluations of an expert panel. Pharmacoepidemiol Drug Saf. 2005;14:885-90.

19. Lei HS, Rahman AF, Haq AS. Adverse drug reaction reports in Malaysia: comparison of causality assessments. Malays J Pharm Sci. 2007;5:7-17.

Cite this article as: Chakraborty A, Ray D, Ghosh R, Roy N, Bhattacharje S. Pattern of adverse drug reactions reporting in two medical colleges of Tripura, India: a cross sectional study. Int J Basic Clin Pharmacol 2017;6:1372-6. 